\title{
The Hidden Shadow of Coronavirus on Education in Developing Countries ${ }^{1}$
}

\author{
Zuheir N Khlaif and Soheil Salha \\ Faculty of Educational Sciences and Teachers' Training, An Najah National University, \\ Nablus, Palestine \\ Shahid Fareed \\ Department of Computer Science, Bahauddin Zakariya University, Multan, Pakistan \\ Hadi Rashed \\ Business Communication Department, Kabul University, Kabul, Afghanistan
}

\begin{abstract}
The aim of this paper is to investigate the challenges associated with emergency remote teaching in the developing countries of Palestine, Libya, and Afghanistan, as reported by middle-school students, their parents, and teachers. These countries have been struggling with an unstable and violent situation for decades. Semi-structured interviews were conducted with 60 participants from the three countries and 60 online classes were observed. Findings revealed that COVID-19 widened the digital gap among students and families, which created challenges in terms of online class attendance. In addition, violation of students' and parents' digital privacy emerged as another key challenge to emergency remote teaching. However, teacher presence and timely feedback in synchronous online sessions strengthened students' engagement within the emergency remote teaching environment. Overall, emergency remote teaching during the COVID-19 crisis deepened inequities across students and infringed upon the digital ethics of students, teachers, and parents.
\end{abstract}

Keywords: COVID-19, Coronavirus, digital inequity, digital privacy

Khlaif, Z.N., Salha, S., Fareed, S., \& Rashed, H. (2021). The hidden shadow of the coronavirus on education in developing countries. Online Learning, 25(1), 269-285. https://doi.org/10.24059/olj.v25i1.2287

\footnotetext{
${ }^{1}$ The motivation for the current study was the findings of Khalif and Salha's (2020) brief report regarding the unanticipated challenges of education during the COVID-19 pandemic. For this paper, the researchers used the same data from the same participants, but developed different research questions on digital privacy, gender inequity, and the specific impact of the digital divide.
} 


\section{The Hidden Shadow of Coronavirus on Education in Developing Countries}

Emergency Remote Teaching (ERT) is an unplanned and sudden shift from traditional inperson education to remote teaching, using technology to deliver teaching and learning materials and activities, due to natural disasters, economic crises, violence, and pandemics. In the past, individual countries have used technology to teach online for a limited time in response to crises and school shutdowns (Czerniewicz et al., 2019; Holzweiss et al., 2020; Khlaif \& Salha, 2020; Shraim \& Khlaif, 2010; Traxler et al., 2019). This year, ERT was implemented in countries across the world to fight the outbreak of Coronavirus (Johnson et al., 2020; Khlaif et al., 2020). ERT is unlike normal online learning: while typical online courses take 3-6 months to design, develop, and deliver to students, ERT materials or lectures were originally designed for face-to-face delivery, and their quality in the remote context can be low (Khlaif \& Salha, 2020). In developing countries in particular, students may also struggle with the digital equity and accessibility of educational resources delivered in the context of a crisis (Czerniewicz et al., 2019; Jones \& Bridges, 2016; Khlaif et al., 2020).

In this study, we investigate the challenges associated with emergency remote teaching in the developing countries of Palestine, Libya and Afghanistan, as reported by middle-school students, their parents, and teachers. In the introductory sections below, we first describe our conceptual framework, which is centered in digital inequity and digital privacy. Next, we describe the context of the three countries under study and lay out our key research questions.

\section{Conceptual Framework}

The dimensions and determinants of the impact of COVID-19 on educational systems within developing countries are wide and varied. In the context of digital learning, however, two issues may represent key challenges to students and their families in developing countries: digital inequity and digital privacy. Below, we review these two issues in more detail, with particular reference to the three developing countries under study.

\section{Digital Inequity}

Digital equity is conceptualized in the framework of resource distribution, technical knowledge and skills, and the impact of Information and Communication Technology (ICT) use (Yuen et al., 2018). Willems et al. (2019) defined digital equity as access to hardware and software and connectivity to the internet to create, share, and exchange high-quality content in a suitable language. Resta et al. (2018) suggested that there are five dimensions of digital equity: hardware, software and connectivity to the internet, high-quality digital content in local languages, creation and sharing of digital content, educators who know technology, and high-quality research and application.

In recent years, with the increasing use of ICT in education, digital inequity has begun to receive more attention from researchers (Kurea, 2015; Yuen et al., 2016). With the shift to remote learning during the COVID-19 crisis, digital inequity has become an even more critical topic (Hall et al., 2020; Khlaif et al., 2020). For example, a recent U.S. study reported that school closures due to the spread of COVID-19 prevented children with disabilities from continuing their learning. These children were from the poorest families who did not have access to technology (Collis \& Vegas, 2020).

In developing counties, the digital divide may be even more stark. Shraim and Khlaif (2010) highlighted that a key challenge of implementing e-learning in the Palestinian educational 
system was students' differential access to devices and high-speed internet. A significant aspect of the digital divide in developing countries is the difference between men's and women's access to and use of technology (Mariscal et al., 2019; Singh, 2017). For example, Elaiess (2017) found a gender divide in Libya, with women and girls having less access to technology, such as the internet, compared with men because of cultural and social issues. Internet cafes for only men are not accepted.. The digital gap in gender is more evident for countries in the global south (such as the three countries under study) than for countries in the global north (such as the U.S.).

\section{Digital Privacy}

Digital privacy refers to the protection of an individual's information and communication that is used or created while using the internet on a computer or personal device (Robertson et al., 2019). It is worth noting that the protection of digital privacy requires the knowledge, the technical practices of online security, institutional privacy procedures, and the skill to conduct several processes for protecting online data $(\mathrm{Li}, 2018)$. Digital privacy is often understood as an individual right that must be respected and secured even when people have different objectives and desires (Ahmed \& Booth, 2016). With advancements in technology, individuals can communicate and leverage data more easily, but are also at increased risk of hackers violating their privacy and data confidentiality (Lustgarten et al., 2020).

Despite the importance of digital privacy, students are often unaware of its meaning or value. For example, Lorenz et al. (2012) conducted a survey of sixty-one participants from Estonia, which examined the relationship between students' awareness of privacy and their level of participation in the online learning environment. The findings of the study revealed that students in the online learning environment did not distinguish between educational social interaction and their privacy. The researchers considered student lack of awareness to be a threat to the student's privacy (Lorenz et al., 2012). Similarly, Siemens et al. (2013) conducted research on Canadian students in a master's degree program to explore their perceptions of privacy and its impact on their engagement within an e-learning environment. The findings of the study revealed that students are not aware of their privacy in the online forums.

Students may be unaware of digital privacy issues because they have not been formally taught about them. Kumar et al. (2019) conducted nine focus group sessions with 25 teachers in elementary school settings across three regions in the north of the U.S. to ascertain the meaning of digital privacy and security. The findings of their study revealed that teachers rarely teach their students about digital privacy and security while using technology. However, teachers and parents themselves may have little understanding about digital privacy. Citizens' concerns and behaviors in terms of digital privacy may also be influenced by political and cultural factors. For example, Fahey and Hino (2020) point out that during the COVID-19 pandemic, some countries (such as France, South Korea, Iran, and Qatar) have taken a "data first" approach to contact tracing and other public health measures, while other countries (such as Germany, Italy, Japan, and the U.S.) have taken a "privacy first" approach.

Studies of digital privacy have not focused on developing countries. However, a unique set of political and cultural factors impact education in developing countries. For example, in Afghanistan, the education system has long struggled with issues revolving around culture, lack of security, and distance; these challenges continue today (Arooje \& Burridge, 2020; Rasmussen \& Kelly, 2016). Many of these challenges are further affected by transparency and quality 
assurance. Thus, levels of awareness and concern about digital privacy in education could be quite different from those found in prior studies.

\section{Context of the Three Countries Under Study}

The three developing counties under study are Palestine, Libya, and Afghanistan. All three countries have been struggling with unstable situations and continuous violence for decades, and thus have implemented ERT many times before the COVID-19 pandemic. Although the three countries are quite distinct, all three share a similar security situation, have experience in education under crisis, used online learning before the COVID-19 pandemic, transformed education into ERT during the COVID-19 pandemic, and have the technological initiatives to integrate technology into teaching and learning. Below, we provide context regarding the educational system of each country.

\section{Libya}

Education policy in Libya is managed from the top down and is influenced by the overall political system of the country. The education system has changed frequently since the Arab Spring in 2011 (Aloreibi \& Carey, 2017). The World Bank (2013) reported significant success in enhancing the literacy rate in Libya by increasing the budget for education and making it free and accessible for all Libyans and implementing new programs to improve education. Conversely, Gadour (2011) argued that the Libyan educational system is still not capable of producing graduates with the necessary skills to compete in a world where knowledge and technology are essential for development in different aspects of the society. Hbaci et al. (2020) found that Libyan educators believe that using technology is still a difficult task, and that schools need computers, internet access, training, and financial support to improve the teachers' technological competencies in teaching and learning. Libyan students may also be underrepresented in terms of their participation in global learning platforms: a recent study of Arab users of the MITx online learning platform found that only 111 per million Libyans used the platform, compared to 1,552 per million in the United Arab Emirates and 383 per million in Egypt (Ruipérez-Valiente et al., 2020).

\section{Palestine}

As an occupied territory, Palestine is subject to a variety of ongoing restrictions (such as checkpoints and other travel restrictions), as well as periodic "security spikes" characterized by unrest, violence, and travel lockdowns, which negatively impact its educational system. For example, students and teachers may be unable to pass through checkpoints in order to reach school in time, or school trips may be canceled due to travel restrictions (Traxler et al., 2019). A recent study conducted by Bruck et al. (2019) confirmed the continued conflict in Palestine decreased the probability to pass the final exam, and the opportunities to get an admission from the university to pursue higher education. To mitigate the negative impact of restriction of mobility on their students' education, many Palestinian teachers have turned to digital technologies (Traxler et al., 2019). Furthermore, the Ministry of Education (hereafter MoE), which is responsible for the administration and development of the Palestinian education system at the levels of preschool, basic education, and secondary education has taken different procedures on the ground to reduce the negative impact of conflict on education such as locating teachers close to their living place and opening new schools in rural areas (Shraim, 2018; Shraim \& Khlaif, 2010). Moreover, the MoE has pursued a variety of initiatives to integrate technology in public schools, such as the Professional Development program (supported by the U.S. through USAID), the Belgium eLearning project (supported by the Kingdom of Belgium), and Smart Learning (supported by the 
local community in Palestine) (Khlaif \& Farid, 2018). As a consequence, Palestinian education is highly digitized at both the managerial and instructional levels (Khlaif et al., 2019). In general, the Palestinian education system is thought to be strong, with an adult literacy rate at more than $90 \%$ (Itmazi. 2020).

\section{Afghanistan}

The education system in Afghanistan is influenced by the Taliban, and therefore there were several changes in the Afghani education system from the Taliban period to the post-Taliban period (Dandawate \& Dhanamjaya, 2019). The decades of conflict almost destroyed the education system in Afghanistan. During the Taliban era, most girls' schools were closed; girls represented only about $6 \%$ of school enrollment, and women were barred from the few Teacher Training Colleges that remained open (Shayan, 2015). For students who did attend school, the curriculum included a religious subject that took up to $50 \%$ of the teaching time (Guistozzi, 2010). Starting in 2002 , girls' enrollment began to rebuild; by 2013, girls represented $38 \%$ of school enrollment, and $32 \%$ of teachers were women (Shayan, 2015). However, enrollment is inequitably distributed across the country; in 2008, $80 \%$ of girls attended school in the Hazara region, while only $10 \%$ did so in several southern provinces (Larson, 2008).

Noorajan (2020) described Afghani online learning as very poor, stating that access to the internet and digital learning resources are still not available in most educational institutions. The digital divide is greater than expected because of the digital inequity to access to technology and the social gap among the Afghani society (Khan et al., 2012). Saay and Norta (2018) claimed that higher education institutions have moved forward in terms of creating a shared, reliable, highspeed, interoperable e-learning structure, a similar system for K-12 is not yet a reality.

\section{Contribution of this Study}

Although much research has been conducted on distance education, there is a lack of research on ERT in developing countries, particularly since the COVID-19 emergency forced schools to close and transfer their education to online classes. This study examines a "hidden shadow" on education across these three countries: the unrevealed impact of ERT during the COVID-19 pandemic on education, including on students, parents, teachers, and quality of content. The study aims to answer the following questions:

- How was Emergency Remote Teaching implemented in middle school settings by instructors in these three countries?

- To what extent did digital inequity create challenges for students and their families?

- To what extent did digital privacy concerns create challenges for students and their families?

\section{Methods}

A qualitative approach was adopted for the current study. The qualitative approach is generally used to describe an intervention or phenomenon in the real-life context in which it occurred (Yin, 2003). The qualitative approach used in the current study was individual semistructured interviews and observations of online learning sessions. 


\section{Participants}

The participants in the study were parents, students, and teachers in middle school settings in Libya, Palestine, and Afghanistan. Sixty participants (20 participants from each country, including 15 teachers, 15 parents, and 30 students) were interviewed to discuss their lived experience with ERT in middle school settings during the COVID-19 pandemic. Furthermore, 60 online classes (4 for each participating teacher) were observed.

Purposeful sampling was used to recruit participants. The criteria for recruiting the participants in the study were having experience in online teaching during the COVID-19 pandemic; living in Libya, Palestine, and Afghanistan; and allowing the online classes to be observed. The participants were recruited through the professional network of the first author, who was working with nonprofit organizations to train teachers on the use of ICT tools in education in these countries. Table 1 presents demographic information about the participants.

\section{Table 1}

Participants' Demographic Characteristics

\begin{tabular}{lcccccc}
\hline \multicolumn{1}{c}{ Participants } & \multicolumn{2}{c}{ Palestine } & \multicolumn{2}{c}{ Libya } & \multicolumn{2}{c}{ Afghanistan } \\
\hline & Male & Female & Male & Female & Male & Female \\
\hline Teachers & 3 & 2 & 2 & 3 & 2 & 3 \\
Parents & 2 & 3 & 2 & 3 & 3 & 2 \\
$\begin{array}{l}\text { Middle school } \\
\text { students }\end{array}$ & 4 & 6 & 3 & 7 & 4 & 6 \\
Total & 9 & 11 & 7 & 13 & 9 & 11 \\
\hline
\end{tabular}

\section{Data Collection}

Semi-structured interviews with 60 participants on Zoom were the main data source of this research. Individual interviews were 20-30 minutes in length and were audio-recorded after obtaining permission from each participant. The interviews with participants from Libya and Palestine were in the Arabic language. The interviews with participants from Afghanistan were in the Dari and Arabic languages.

The secondary data collection approach was observations of online classes. Researchers observed four online classes for each teacher. The main criterion for teachers to participate in the study was allowing their different online classes to be observed. The researchers observed 60 online classes from the three countries, which took around 50 hours. Forty online classes were in the Arabic language and 20 were in the Dari language (the Afghani official language). The classes comprised students from different backgrounds and cultures. All the students, parents, and teachers participated in the study on a voluntary basis.

\section{Data Analysis}

The data analysis process started with the manual transcription of the interview audio files. The transcribed files in the Dari language were translated into the Arabic language to facilitate the 
data analysis process. The researchers individually coded the data into themes and subthemes from all the data sources by using thematic analysis (Creswell \& Creswell, 2017). Through thematic analysis, researchers analyze, categorize, and report patterns in the data. After constructing the themes that emerged in the analysis of the interview data, the researchers used these themes to analyze the observations of online classes.

In terms of the analysis of the observations of online classes, the researchers wrote notes on the structure of the classes and audio-recordings of the sessions to answer the first research question. Furthermore, the data from the observations of online classes were used to support themes and subthemes that emerged in the individual interviews.

\section{Trustworthiness}

After transcribing the interviews, the researchers sent all the written transcripts to participants for checking, asking them to verify the content for accuracy. Moreover, participants were asked to write notes, rewrite content, and add new information on the transcripts. Participants' transcripts were not altered by the researchers. When the final themes had been constructed, a professor in educational technology was asked to select a small portion of the transcription and analyze it based on the constructed themes to check the accuracy of the themes. In the Results section below, transcript excerpts are labeled according to the participant's role (Parent, Teacher, or Student), country $(\mathrm{A}=$ Afghanistan, $\mathrm{L}=$ Libya, or $\mathrm{P}=$ Palestine $)$ and a personal identification number.

\section{Results}

\section{Research question \#1: How was Emergency Remote Teaching implemented in middle school settings by instructors in these three countries?}

Based on the analysis of the observations of online classes, the researchers categorized the implementation of ERT by schools and teachers in the three countries into three themes: type of online learning classes, students' engagement, and the design and delivery of online instruction.

\section{Type of Online Learning Classes}

Most of the teachers in the three countries used both synchronous and asynchronous tools to deliver instruction to the learners in the middle school settings. Typically, teachers created their asynchronous class using Edmodo or Google Classroom, and posted links to synchronous Zoom sessions on the class wall. Most of these teachers also recorded the synchronous sessions and posted the recordings for students who may have missed class. Students needed to log into the virtual classes to access the recorded sessions. All the teachers used free versions of the Zoom application, Google Classroom, and Edmodo.

However, some teachers used other asynchronous platforms to deliver instruction and to communicate with their students, and they rarely used synchronous sessions. A follow-up question was sent to these teachers about the reasons for not using synchronous sessions. Typically, teachers responded that most of their students did not have access to the internet because of the electricity in Gaza in Palestine and in Afghanistan being cut off.

Despite differences in the type of online instruction among the teachers from the three countries, all teachers' instruction shared the following common features: it was free, it was easy 
to use, students had to enroll in the platform to access content, and technology tools were integrated.

\section{Types of Content Delivered}

Various types of content were used by teachers to instruct students, including interactive activities designed in open-source platforms, educational videos from YouTube, PowerPoint slides designed by teachers and students, pictures, infographics, and whiteboard animation. Teachers from Palestine and Afghanistan focused on using simple technological tools to design and deliver the instruction, most of which were from open-source platforms. They integrated simple tools to design and deliver interactive content to the students. However, the Libyan teachers depended only on one tool to design and develop instruction, which was the Edmodo platform.

Few teachers assigned online tasks or activities to their students in the synchronous sessions, as they reported they did not want to distract students in the online sessions. Instead, they assigned activities asynchronously using Edmodo or Google Classroom.

In synchronous online sessions, teachers shared their screens, used different features of the online platform such as the whiteboard and polls, and used breakout rooms to allow students to work on assignments in small groups. Depending on the type of instruction, teachers allowed students to share their screen.

\section{Students' Interaction}

Teachers tried to support students' engagement and interaction with each other in the synchronous and asynchronous sessions by designing and delivering activities. A few teachers gave students the opportunity to interact with the instructor or with their peers. These teachers delivered online individual and group activities. Teachers asked students to work on these activities online by forming groups and giving them the option to share their screens to present their work to their peers. Other students were able to interact with their peers by providing text and verbal comments by using chat and audio features.

Many of the students engaged and interacted with their teachers through text questions written on the chat tab. In addition, some students engaged in answering their peers' questions on the chat tab.

Some female students from the three countries were reluctant to participate verbally in the online discussion. However, we noticed that these students were active in the asynchronous discussion on the platform. The researchers asked the female students a follow-up question about their engagement with the platform and discussions. Feedback from participants indicated that students had various reasons for choosing to participate in asynchronous rather than synchronous interaction, including personal reasons and cultural and religious reasons. (We discuss these reasons in more detail under Research Question 3.)

Moreover, the researchers noticed that the presence of teachers on the platform and timely feedback encouraged students to complete their assignments and interact with their peers. Students from Afghanistan were more engaged in asynchronous activities than Palestinian students. Observations suggested that the reason for this was that unlike the Afghani teachers, Palestinian teachers did not interact with their students in asynchronous platforms. Libyan students engaged and interacted in both synchronous and asynchronous platforms less than the Afghani and Palestinian students. 


\section{Challenges of ERT}

All the participants from the three countries reported that ERT was a big challenge for them since it was unplanned, and students, teachers and parents were unprepared to shift to online learning. Most of the teachers in the three countries agreed that "this was not the first time we moved to online teaching during a crisis" (Teacher P2) and that previous transformation had been for "specific schools in specific districts due to violence" (Teacher A4). Implementing ERT on a large scale in the three countries caused pressure and anxiety for families in these countries. A parent from Afghanistan said: "Using online learning during the COVID-19 crisis put me and my wife under pressure. We have three kids in school... We do not have enough devices and enough knowledge about online teaching" (Parent A1).

\section{Research question \#2: To what extent did digital inequity create challenges for students and their families?}

All the participants from the three countries reported that moving to ERT suddenly increased the digital gap in the learning process. In addition, they all reported that digital inequity put them under high pressure and caused anxiety - particularly since they did not know when this state of emergency would end and allow them to return to face-to-face learning. Overall, the researchers identified three main themes: inequity in internet and hardware, quality of digital content, and inequity based on gender.

\section{Inequity in Internet and Hardware}

\section{Internet Broadband Connectivity}

Teachers from Libya, Afghanistan, and Palestine noted the weakness of internet bandwidth as an element that hindered their ability to provide timely instruction to students, ultimately affecting student engagement. Although teachers in all three countries mentioned the issue, it was reported less in the Palestinian context than in the Afghani and Libyan contexts. Teachers and students who referred to the inequity in internet reported that access to internet broadband was one of the major barriers to implementing ERT during the COVID-19 pandemic.

For example, a teacher from Afghanistan reported that "[the] internet nowadays is weak because a lot of people were trying to attend online classes... It cannot help me prepare instruction and deliver it to my students" (Teacher A3). Researchers observed that students from rural areas in all three countries were at more of a disadvantage in terms of the availability and reliability of the internet than their peers from large cities.

I live in a small village north of Gaza, Palestine. I did not attend online classes... I missed most of them because the electricity is cut off all the time... Even if we have electricity, the internet is weak. I asked my relative who lives in Gaza city to send me the recorded files to view them when electricity is available (Student P3).

A female student from a rural area in Afghanistan stated: "I usually go to my uncle's house to attend online classes because we do not have the internet at home" (Student A3).

The participants from Libya reported that families' financial situations influenced their connectivity to the internet.

I am a teacher in Tripoli. I have not received my salary for the last year, so how can I pay for the internet? My priority is to pay for food and living expenses... Moving to emergency remote teaching was sudden, and it is difficult to adopt it in a short time (Parent L3). 


\section{Inequity in Hardware}

Families from all three countries reported that some households have too few technological devices based on the number of children enrolled in schools and universities, especially in families in which the father or mother or both are enrolled in a graduate program at a university. A female student from Libya reported, "I cannot attend synchronous classes because my sister is using the device [laptop] when it is time for the class" (Student L2). A female student from Palestine stated that "before this crisis [COVID-19], I used to use my mom's iPhone to finish my assignments, but now I cannot do this because she uses it to teach her students" (Student P4).

A parent from Libya reported:

Because of the stay at home rule, I lost my job, and it is difficult to buy a new device for my kids to attend online learning. I asked their teacher to provide me the recorded teaching materials to use them by my children (Parent L3).

A male student from Afghanistan stated: "I have two sisters, one in high school and the older one at the university. All of us are using the same desktop... My dad cannot buy an additional computer for us" (Student A9). A parent from Palestine said, "I cannot buy more devices because I have not received my salary in the last six months because of Coronavirus" (Parent P3).

\section{Quality of Digital Content}

Parents, teachers, and students agreed that the quality of digital content delivered by teachers in both synchronous and asynchronous sessions was low. For example, Libyan parents and students mentioned the low quality of course content for math and English, while Palestinian and Afghani students and parents reported the low quality of learning materials and content in science. Teachers believed the low quality of course content was a result of the sudden transition to remote learning contexts.

We moved to online teaching within 24 hours. I do not have time to plan and design suitable content for my students... The teaching online is completely different from teaching face to face... It needs specific teaching strategies, specific content, which takes a lot of time to prepare (Teacher A3).

Other teachers from Libya and Palestine reported that they were "unprepared" to design interactive content, stating that they "do not have a team to design" and "do not know the tools to use in the design process" (Teacher L1, Teacher L3, Teacher L4; Teacher P4, Teacher P5).

Students from Afghanistan complained about the quality of the assignments and the grading system.

The content is related to the lesson in the book, but when I went to do the assignment, it was unclear. I do not feel there was a connection between the assignment and the material. In addition, I do not know how my teacher will grade me (Student A4).

Some parents from Palestine and Afghanistan were struggling to teach and assist their children because they do not have experience with the design of digital content. A Palestinian parent said, "I usually teach my children and help them finish their tasks and activities but now I do not know how to start with them... I asked my brother, who is a teacher, to help them" (Parent P2). A parent from Afghanistan stated: "I am not educated in using technology. It is difficult for me to teach my kids this type of content" (Parent A5). 


\section{Inequity Based on Gender}

Most students and parents, and some teachers, believed that online course design and delivery was biased based on gender. For example, female students reported that course materials and activities tended to focus on males by showing photos of boys or using boys' names.

Our observational data supported female students' perceptions that teachers from all three countries privileged male students by using gendered language, referring mostly to boys' names, allowing male students to speak more frequently, and often interrupting female students.

My teachers are biased toward males in online classes. Since the beginning of teaching online two months ago, I have only been allowed to use the mic twice for two or three minutes, but some males talk more than all the females (Student P4).

A female student from Libya said: "In the presentation of our project, my teacher did not give us an opportunity to present in the same way as males and in mixed teams. He asked if I prefer males to present the project... I like to discuss my ideas, but I am not allowed to" (Student L3).

The inequity based on gender was not only due to teachers, as some families did not allow their female children to use the microphone. A female student from Libya stated: "My dad put restrictions on using the microphone and camera while using his laptop for online learning" (Student L5). A Palestinian female student mentioned that her mother allowed her to use the internet for learning without opening the mic and the camera (Student P2).

\section{Research question \#3: To what extent did digital privacy concerns create challenges for students and their families?}

According to the data analysis, a new theme related to the ERT during the COVID-19 crisis was mentioned by the participants, which was digital privacy. Most of the participants in the current study stated that teaching and learning in the ERT environment should be managed professionally and ethically by teachers and students.

All participants expressed concerns about digital privacy, and most of the students reported that their digital privacy was violated by one of their family members or by their teachers. Furthermore, families stated that sharing devices such as smartphones, laptops, or desktops is considered as violating individual privacy. In general, perspectives on privacy seemed related to two key themes: gender differences in privacy and sharing devices or internet access.

\section{Gender Differences in Privacy}

As mentioned earlier, many female students mentioned that their families did not allow them to use their camera or microphone during class. A follow-up question was sent to the students asking why their families were concerned about the camera and microphone. Below, we draw from these responses as well as students' original interviews.

Due to security concerns, cultural traditions, or religious strictures, many female students and their families felt their personal images should remain private. For example, one parent said, "We are living in a bad situation because of violence and security. I am concerned about her [daughter] privacy in online learning. I do not know how to protect her" (Parent A3). In some districts in Afghanistan, Libya, and Palestine, it is considered inappropriate for families to allow their children to share photos, videos, or even to appear talking in a video clip. Other families from these countries consider themselves open-minded and allow their children to share videos and 
photos and use a webcam on the internet; however, these families were a minority. Overall, many female students felt their privacy was threatened by teachers as well as other students.

First, some teachers asked female students to engage in practices that the students or families felt were inappropriate. For example, the researchers noticed that some male teachers asked students to open their camera at the beginning of the session. Some of the girls refused to open it, with one girl saying, "I do not like to open my camera for personal reasons" (Student P1), and the teacher respected their privacy. During the online sessions, some teachers asked students to share their desktop; some students agreed to share it while others refused to share it, with one saying, "I have personal pictures in the background on my computer" (Student A2). In interviews, a few other female students reported that their teachers asked them to open the webcam, which they considered a violation of their digital privacy and reported to their families. One student asked, "Personal information on social media and in the online classes is private information. I do not like to use the camera, so why did my teacher asked me to open the camera?" (Student L4). Other families did not allow their girls to attend online classes if they were asked to share their information on social media or share their laptop screen.

Second, female students felt that many of their male peers did not know the "boundaries" or work "professionally" (Student A5) in the new online learning environment. A female student from Afghanistan expressed anger about some of her male friends who looked for her social media profile and sent her a friend request. Some female teachers from Libya and Afghanistan also reported that many girls complained about the bad conduct of their peers, which included taking screen shots of the online sessions and posting them on social media pages, trying to add them as friends on social media, and sharing their emails on the chat tab in the online sessions to contact them.

In contrast, most of the male students did not care about their privacy. They were willing to open their camera and to share their desktop and shared no concerns about these practices in their interviews.

\section{Sharing Devices or Internet}

Parents from all three countries reported they were forced to share their own smartphones, laptops, or desktops with their children for schooling purposes, which they felt was a violation of individual privacy. A parent from Palestine stated:

Because we do not have extra devices, sometimes I share my smartphone with my son and allow him to use it... My accounts on social media are open, and I share my thoughts with my close friends... Allowing a family member to share my device puts my digital privacy at risk (Parent P3).

A Libyan parent reported that she does not like to share her laptop with her children. She said, "I am lawyer, and all of my clients' files are stored on my computer... Honestly, when I let my kids use my laptop, I observed them" (Parent L4). We asked her a follow-up question about restricting access to her files by using a password. The answer was: "I do not have high skills in computers to protect myself... I would appreciate it if you could help me" (Parent L4). A woman from Afghanistan reported that her husband asked her if he could share her smartphone in his online session. "My husband is a science teacher and he asked if he could use my phone... At the beginning, I hesitated because I have my sister's wedding pictures on it” (Parent A3). 
In addition to sharing devices, many families shared their internet access points with neighbors. This practice was common in Palestine and Afghanistan but was less common in Libya since buying an internet package is cheaper than in Palestine and Afghanistan. "No, I do not like to share internet with others. It is cheap... I have high internet speed for less than $\$ 10$ " (Parent L1).

When families shared internet with neighbors, parents worried that their children could be stalked by others on their network. A parent from Afghanistan reported: "We share internet with one of our neighbors because it is expensive to buy an internet package alone... My daughter told me that our neighbors' son knows everything about her online account and sent her a friend request" (Parent A1). Students from Libya and Palestine reported that they do not feel safe and secure in the online environment when they share internet with their neighbors. For example, a female student from Palestine said: "When I post anything on social media, our neighbors' son was the first to like or comment. I feel he is waiting for me to write a post" (Student P8).

\section{Discussion}

The aim of the study was to explore the challenges of ERT during the COVID-19 crisis in three developing countries, Libya, Palestine, and Afghanistan. A qualitative approach was adopted to achieve this aim. Moving suddenly from face-to-face teaching to ERT complicated and disrupted the educational system in these countries, which had already been affected by violence and unstable policy, as well as the weaknesses of the infrastructure and the bad economic situation. Although teachers tried their best to foster students' engagement in online learning sessions, they sometimes failed because of the digital inequity among students and families.

Teachers and students in the developing countries used synchronous and asynchronous free tools to continue teaching and learning in the ERT, and teachers on both asynchronous and synchronous platforms provided support and encouraged students to engage in online activities. Teachers relied on their own technology solutions because there was no well-designed and secure online system or platform for teaching and learning. As a result, learners' digital privacy was threatened, and consistent with previous studies, the quality of content in the emergency context was low compared with content delivered in a well-planned online learning context (Hodges et al., 2020; Khlaif et al., 2020; Mohmmed et al., 2020; Whittle et al. (2020).

Our results found a number of inequities between students. Some parents could not provide their children with technological devices and families in rural and remote places encountered difficulties in getting connected to internet broadband, which reduced students' engagement in online synchronous sessions compared with online asynchronous sessions. Girls were also less active in synchronous online sessions than boys, due in large part to their hesitancy to share their personal images, but they were more active and productive in the asynchronous platforms. These results align with previous studies suggesting that digital inequity negatively influences the online learning process (Khidhir et al., 2020; Khlaif \& Salha, 2020; Khlaif et al., 2020).

We also found that digital privacy was a major concern for both parents and students. Most families were concerned about daughters opening their webcams or sharing their screens. Parents were reluctant to share their own devices for their children's schooling, and worried that their children's activities could be monitored by neighbors via shared internet access points. In general, 
violation of students' and parents' digital privacy increased during the coronavirus ERT, which reduced students' engagement in online classes.

The concepts of digital inequity and digital ethics are still very limited, underrated, and unclear in developing countries such as Palestine, Afghanistan, and Libya. Both were eroded in the coronavirus ERT setting, which had a negative influence on students' engagement in online classes. The absence of these concepts and related processes of instructional design among teachers in ERT settings was obvious, which deepened digital inequity and damaged digital privacy. To address these issues, the Ministries of Education in these countries may wish to consider three key actions. First, they could provide students and teachers with devices and reduce internet fees to make the internet available to a wide range of citizens. Second, they could develop a clear vision about digital privacy. Finally, develop a shared technology platform across the K-12 system that will benefit learners and train teachers on it. 


\section{References}

Affouneh, S., Salha, S., \& Khlaif, Z. N. (2020). Designing quality e-learning environments for emergency remote teaching in Coronavirus crisis. Interdisciplinary Journal of Virtual Learning in Medical Sciences, 11(2), 1-3.

Ahmed, A. \& Booth, D. (2016). The digital privacy laws and practices in the Jersey island. Procedia Computer Science, 98, 163-168. https://doi.org/10.1016/j.procs.2016.09.026

Aloreibi, A., \& Carey, M. D. (2017). English language teaching in Libya after Gaddafi. In English language education policy in the Middle East and North Africa (pp. 93-114). Cham, Springer. https://doi.org/10.1007/978-3-319-46778-8_7

Arooje, R., \& Burridge N. (2020). School education in Afghanistan. In P. Sarangapani \& R. Pappu (Eds.), Handbook of education systems in South Asia. Springer. https://doi.org/10.1007/978-981-13-3309-5_10-1

Brück, T., Di Maio, M., \& Miaari, S. H. (2019). Learning the hard way: The effect of violent conflict on student academic achievement. Journal of the European Economic Association, 17(5), 1502-1537.

Creswell, J. W., \& Creswell, J. D. (2017). Research design: Qualitative, quantitative, and mixed methods approaches. Sage.

Dandawate, V. S., \& Dhanamjaya, M. (2019). A review of the open-access scenario in Afghanistan. Library Hi Tech, 37(4), 660-668. https://doi.org/10.1108/LHT-01-20190020

Elaiess, R. (2017). Digital divide in Libya: A general assessment. International Research: Journal of Library and Information Science, 7(3), 1-9.

Fahey, R. A., \& Hino, A. (2020). COVID-19, digital privacy, and the social limits on datafocused public health responses. International Journal of Information Management, 55, 102181.Gadour, A. (2011). Power and struggle for education in Libya. In R. G. Sultana (Ed.), Educators of the Mediterranean ... ...up close and personal. Comparative and international education (a diversity of voices) (vol. 9, pp. 121-131). Sense Publishers. https://doi.org/10.1007/978-94-6091-681-6_11

Guistozzi, A. (2010). Nation-building is not for all: The politics of education in Afghanistan. Retrieved from https://www.afghanistan-analysts.org/en/special-reports/nation-buildingis-not-for-all-the-politics-of-education/

Hbaci, I., Ku, H. Y., \& Abdunabi, R. (2020). Evaluating higher education educators' computer technology competencies in Libya. Journal of Computing in Higher Education, 1-18. https://doi.org/10.1007/s12528-020-09261-z

Hodges, C., Moore, S., Lockee, B., Trust, T., \& Bond, A. (2020). The difference between emergency remote teaching and online learning. Educause Review, 27(1), 1-12.

Holzweiss, P. C., Walker, D. W., Chisum, R., \& Sosebee, T. (2020). Crisis planning for online students: Lessons learned from a major disruption. Online Learning, 24(2), 22-37. 
Itmazi, J. (2020). Open educational resources in Palestine. In R. Huang, D. Liu, A. Tlili, Y. Gao \& R. Koper (Eds.), Current state of open educational resources in the "belt and road" countries. Lecture notes in educational technology. Springer. https://doi.org/10.1007/978981-15-3040-1_8

Johnson, N., Veletsianos, G., \& Seaman, J. (2020). US faculty and administrators' experiences and approaches in the early weeks of the COVID-19 pandemic. Online Learning, 24(2), 6-21.

Jones, M., \& Bridges, R. (2016). Equity, access, and the digital divide in learning technologies. Wiley Handbook of Learning Technology, 327-347.

Khan, G. F., Moon, J., Swar, B., Zo, H., \& Rho, J. J. (2012). E-government service use intentions in Afghanistan: Technology adoption and the digital divide in a war-torn country. Information Development, 28(4), 281-299. https://doi.org/10.1177/0266666912438879

Khlaif, Z. N., \& Farid, S. (2018). Transforming learning for the smart learning paradigm: Lessons learned from the Palestinian initiative. Smart Learning Environments, 5(1), 12.

Khlaif, Z. N., \& Salha, S. (2020). The unanticipated educational challenges of developing countries in Covid-19 crisis: A brief report. Interdisciplinary Journal of Virtual Learning in Medical Sciences, 11(2), 130-134.

Khlaif, Z. N., Salha, S., Affouneh, S., Rashed, H., \& ElKimishy, L. A. (2020). The Covid-19 epidemic: teachers' responses to school closure in developing countries. Technology, Pedagogy and Education, 1-15.

Kurea, G. M. (2015). The implementation of the two third gender rule in the devolved government as stipulated in the Kenyan Constitution: The case study of Meru County (Doctoral dissertation, University of Nairobi). Retrieved from: http://erepository.uonbi.ac.ke/bitstream/handle/11295/94524/Kurea_The\%20Implementat ion $\% 20$ of $\% 20$ the $\% 20$ Two $\% 20$ Third $\% 20$ Gender $\% 20$ Rule $\% 20$ in $\% 20$ the $\% 20$ Devolved $\% 2$ 0Government $\% 20$ as $\% 20$ Stipulated $\% 20 \mathrm{in} \% 20$ the $\% 20$ Kenyan $\% 20$ Constitution.pdf?seque nce $=3 \&$ is Allowed $=y$

Li, X. (2018). Understanding eHealth literacy from a privacy perspective: eHealth literacy and digital privacy skills in American disadvantaged communities. American Behavioral Scientist, 62(10), 1431-1449. https://doi.org/10.1177/0002764218787019

Lorenz, B., Sousa, S., \& Tomberg, V. (2013). Privacy awareness of students and its impact on online learning participation-A case study. In T. Ley, M. Ruohonen, M. Laanpere, \& A. Tatnall (Eds.), OST 2012. IFIP AICT (vol. 395, pp. 189-192). Springer.

Mariscal, J., Mayne, G., Aneja, U., \& Sorgner, A. (2019). Bridging the gender digital gap. Economics: The Open-Access, Open-Assessment E-Journal, 13(9), 1-12.

Mohmmed, A. O., Khidhir, B. A., Nazeer, A., \& Vijayan, V. J. (2020). Emergency remote teaching during Coronavirus pandemic: The current trend and future directive at Middle East College Oman. Innovative Infrastructure Solutions, 5(3), 1-11. 
Noorajan A. (2020). A critical reflection of teacher education policies and programs in Afghanistan. In K. Pushpanadham (Ed.), Teacher education in the global era. Springer. https://doi.org/10.1007/978-981-15-4008-0_14

Rasmussen, P. E., \& Kelly, A. (2016). Education sector analysis Afghanistan. Pouras Consult. https://www.globalpartnership.org/sites/default/files/education-sector-analysisafghanistan.pdf.

Resta, P., Laferrière, T., McLaughlin, R., \& Kouraogo, A. (2018). Issues and challenges related to digital equity: An overview. Second handbook of information technology in primary and secondary education (pp. 1-18). https://doi.org/10.1007/978-0-387-73315-9_44

Ruipérez-Valiente, J. A., Halawa, S., Slama, R., \& Reich, J. (2020). Using multiplatform learning analytics to compare regional and global MOOC learning in the Arab world. Computers \& Education, 146, 103776. https://doi.org/10.1016/j. compedu.2019.103776

Shraim, K., \& Khlaif, Z. (2010). An e-learning approach to secondary education in Palestine: Opportunities and challenges. Information Technology for Development, 16(3), 159-173. https://doi.org/10.1080/02681102.2010.501782

Traxler, J., Khaif, Z., Nevill, A., Affouneh, S., Salha, S., Zuhd, A., \& Trayek, F. (2019). Living under occupation: Palestinian teachers' experiences and their digital responses. Research in Learning Technology, 27, 1-18. https://doi.org/10.25304/rlt.v27.2263

United Nations. (2015). Sustainable development goals. Retrieved January 18, 2021, from https://sustainabledevelopment.un.org

UNESCO. (2020). COVID-19 education response. Retrieved January 18, 2021, from https://en.unesco.org/covid19/educationresponse/globalcoalition

Whittle, C., Tiwari, S., Yan, S., \& Williams, J. (2020). Emergency remote teaching environment: A conceptual framework for responsive online teaching in crises. Information and Learning Sciences, 121(5/6), 311-319. https://doi.org/10.1108/ILS-04-2020-0099

Willems, J., Farley, H., \& Campbell, C. (2019). The increasing significance of digital equity in higher education. Australasian Journal of Educational Technology, 35(6), 1-8. https://doi.org/10.14742/ajet.5996

World Bank. (2013). Libya: World development indicators. Retrieved January 18, 2021, from http://data.worldbank.org/country/libya\#cp_wdi

Yuen, A., Park, J., Chen, L., \& Cheng, M. (2018). The significance of cultural capital and parental mediation for digital inequity. New Media \& Society, 20(2), 599-617. https://doi.org/10.1177/1461444816667084 